
\title{
$\begin{array}{ll}\text { Research Square } & \begin{array}{l}\text { Preprints are preliminary reports that have not undergone peer review. } \\ \text { They should not be considered conclusive, used to inform clinical practice, } \\ \text { or referenced by the media as validated information. }\end{array}\end{array}$
}

\section{Efficient tetracycline removal from aqueous solutions using ionic liquid modified magnetic activated carbon (IL@mAC)}

\section{Edris Bazrafshan}

Health Sciences Research Center, Torbat Heydariyeh University of Medical Sciences, Torbat Heydariyeh 33787 95196, Iran

\section{Amin Allah Zarei}

Department of Environmental Health Engineering, Torbat Heydariyeh University of Medical Sciences,

Torbat Heydariyeh 33787 95196, Iran

\section{Leili Mohammadi ( $\square$ lailimohamadi@gmail.com)}

Infectious Diseases and Tropical Medicine Research Center, Resistant Tuberculosis Institute, Zahedan University of Medical Sciences, Zahedan 98167-43463, Iran

\section{Muhammad Nadeem Zafar ( $\nabla$ znadeempk@gmail.com )}

Department of Chemistry, University of Gujrat, Gujrat 50700, Pakistan https://orcid.org/0000-00022109-7601

\section{Maryam Foroughi}

Health Sciences Research Center, Torbat Heydariyeh University of Medical Sciences, Torbat Heydariyeh 33787 95196, Iran

\section{Summan Aman}

Department of Chemistry, University of Gujrat, Gujrat 50700, Pakistan

\section{Faezeh Sabri}

Health Sciences Research Center, Torbat Heydariyeh University of Medical Sciences, Torbat Heydariyeh 33787 95196, Iran

\section{Amir Hossein Mahvi}

Department of Environmental Health Engineering, Tehran University of Medical Sciences, Tehran, Iran

\section{Farahnaz Barahuie}

Faculty of Industry and Mining (Khash), University of Sistan and Baluchestan, Zahedan 9816745845 , Iran

\section{Research Article}

Keywords: Antibiotics, Tetracycline, Langmuir, lonic Liquid modification, Magnetic activated carbon 
DOI: https://doi.org/10.21203/rs.3.rs-943174/v1

License: (a) (i) This work is licensed under a Creative Commons Attribution 4.0 International License. Read Full License 


\section{Abstract}

Tetracycline (TCy) belongs to PPCPs is such an widely used antibacterial drug, which is discharged from urban wastewater treatment plants or agricultural effluents. Due to low metabolism, poor absorption, overuse, and misuse, TCy is considered as threat to environmental and its removal from waste-water is vital. In this research, a novel ionic liquid modified magnetic activated carbon nanocomposite (IL@mAC) was synthesized, characterized, and the adsorption efficiency of IL@mAC for removal of TCy was investigated under different operational parameters of $\mathrm{pH}(3-11)$; dose of IL@mAC $(0.01-0.1 \mathrm{~g} / 50 \mathrm{~mL})$; reaction time (30-240 min), and initial TCy concentration (50-1500 mg/L). The IL@mAC characterization was done using XRD, VSM, SEM-EDX, BET, and FTIR. Results of equilibrium experiment showed that the highest removal efficiency ( 98\%) was obtained using $0.06 \mathrm{~g}$ of IL@mAC in $135 \mathrm{~min}$ at pH 7 and temperature $303 \mathrm{~K}$. Considering the correlation coefficients $\left(\mathrm{R}^{2}\right)$ for different adsorption models, it can be deduced that adsorption of TCy onto IL@mAC is better followed by Langmuir (0.9977) in comparison to Freundlich (0.9412), and Temkin (0.9536) models. Furthermore, Langmuir adsorption capacity was observed to be $666.7 \mathrm{mg} / \mathrm{g}$. The regeneration study showed that IL@mAC retained around 85\% TCy adsorption efficiency after 6th cycle. Finally, the present study indicates that the IL@mAC is of a high applicability and has extremely high adsorbent capacity to remove TCy from water compared to most of other benchmark adsorbents reported in literature.

\section{Introduction}

Antibiotics, which are a group of potent medicines have been widely used to cure infectious human and animal diseases [1]. However, the same compounds have also been considered as new environmental pollutants categorized under the PPCPs (pharmaceuticals and personal care products) class [2]. Veterinary antibiotics (like tetracycline (TCy)) have been widely administrated for combating bacterial infection in humans as well as for improvement of animals' feed and growth efficiency [3]. Improper and extensive use of antibiotics leads to their intensive discharge into waste-water treatment facilities (WWTFs), which is due to their incomplete absorbance or metabolism in livestock or human bodies [4]. From another viewpoint, conventional waste-water treatment units are not sufficiently able to degrade these products, which in turn, results in their constant discharge into the environment via different routes including wastewater sludge, effluents, as well as agricultural runoffs [5]. Consequently, the frequent occurrence of pharmaceutical contaminants has turned to a new severe challenge because of the adverse impacts they impose on both ecosystems as well as human health [5].

TCy is an antibacterial agent ranked as the secondly worldwide used antibiotic in aquaculture, human therapy, and veterinary medicines [5]. Nevertheless, due to low metabolism, poor absorption, overuse, and misuse, nearly most of the administered TCy (80-90\%) penetrates into aquatic ecosystems [6]. Therefore, TCy is considered among the most occuring antibiotics in water bodies via water discharged from urban wastewater treatment plants or agricultural effluents [6]. 
The potential environmental risks pertaining to TCy are mainly contributed to their broad-spectrum antimicrobial features [7]. As the occurrence of antibiotics may lead to changes in microbial diversity and metabolism, the presence of TCy is supposed to be of adverse impacts on environment as well as human health [8]. The catastrophic outcomes, including dispersion of the genes resistant to antibiotics (that may no longer to be treated with current drugs), because of ineffectiveness of traditional treatment systems, have resulted in the need for more studies on cost-effective and efficient processes for TCy-containing waste-water treatment [9]. Various techniques have been established for remediation of antibioticscontaining solutions, such as catalytic degradation, chemical oxidation, and membrane filtration etc. [10], however various drawbacks are associated with these techniques such as toxic byproducts, sludge formation, expensive, and controversial affects when used at real scale [11].

Because of no harmful byproducts and lower costs among the various technologies investigated for removing persistent and/or resistant compounds from aqueous solutions, the most promising technology seems to be adsorption $[12,13]$. Carbon-based materials are still regarded as the most attractive option amongst the most widely used adsorbents, and among them, a few studies have been conducted on TCy elimination [14]. Activated carbon (AC) offers an attractive and inexpensive medium for removing inorganic and organic pollutants from aqueous solutions [15]. Given its porous structure and higher surface area, AC can adsorb compounds and gases (e.g. phenols, chlorophenols, and pesticides) [16] in an efficient manner [17]. Also, AC can be easily utilized and functionalized as efficient adsorbent for contaminants [18]. Nevertheless, the small particle size makes them hard to be removed from aqueous solutions [19]. To enhance the separation properties of powder AC, various methods have been originated and most effective is magnetic separation creating magnetic properties in AC [20]. Magnetic AC (mAC) with superparamagnetic particles can be recovered by applying an external magnetic field very swiftly and can be reused without losing the active sites [21].

Ionic liquids (ILs) have been categorized among organic salts made up of organic or inorganic anions and organic cations. ILs have numerous unique physicochemical characteristics, including lower toxicity, satisfying stability, tunable miscibility, and insignificant vapor pressure. Therefore, ILs are considered as favorable "green" materials used for various analytical applications [22] and have become an extremely popular item in separation and purification research. Especially, the magnetic materials functionalized with ILs have become more popular recently. Even though, ILs could not retain their liquid state while being modified on the materials surfaces, the other distinctive characteristics including low volatility and polarity have remained as a challenge. Also, the performance of the resulting materials can be improved by introducing the IL moieties leading to a wide range of applications [23].

Thus, to integrate the above-mentioned merits, a novel type of material was developed by modifying the surface of mAC with IL called as ionic liquid modified magnetic activated carbon nanocomposite (IL@mAC) and used for the removal of TCy from water. This research was aimed to examine the effect of IL@mAC nanocomposite on removing TCy from aqueous environments through the following consecutive phases; (i) IL@mAC nanocomposite was prepared and characterized, (ii) the as-prepared 
pH, IL@mAC dose (mg/L), and time (min), (iii) adsorption isotherms were determined to facilitate the results generalization for real-scale applications. Further response surface methodology (RSM) was also applied to observe the correlation of adsorption factors as function of TCy removal. At last regeneration ability of IL@mAC to remove TCy was also investigated. It is noteworthy that to the best of our knowledge, this is the first report of synthesis and application of a new nanocomposite (IL@mAC) in TCy removal from water.

\section{Materials And Methods 2.1. Chemicals}

For the preparation of $\mathrm{mAC}$, the analytical grade $\mathrm{AC}$ powder was purchased from Merck Company (Merck, Darmstadt, Germany). Ferric chloride hexahydrate $\left(\mathrm{FeCl}_{3} .6 \mathrm{H}_{2} \mathrm{O}\right)$, 1-vinyl-3-butylimidazolium hexafluorophosphate (IL), acetonitrile (ACN), azobisisobutyronitrile, ethanol (EtOH), and TCy were also supplied by Merck Company (Merck, Darmstadt, Germany).

\subsection{Synthesis of IL@mAC 2.2.1. Preparation of $\mathrm{mAC}$}

For the preparation $\mathrm{mAC}$, the $\mathrm{AC}$ powder was dissolved in $\mathrm{FeCl}_{3} \cdot 6 \mathrm{H}_{2} \mathrm{O}(10 \% \mathrm{w} / \mathrm{v})$ alcoholic solution and kept for 24 hours to complete enough magnetization. After that, the prepared mAC was set apart to dry in open air at $25^{\circ} \mathrm{C}$. Then, the mAC was charred and ignited in an assembly consisting of a wire gauze with an electric heater having an exhaust outlet for gases and an inlet for nitrogen [24].

\subsubsection{Synthesis of IL@mAC}

The IL, 1-vinyl-3-butylimidazolium hexafluorophosphate was utilized to modify mAC. The mAC mixed with IL and ACN at different weight ratios of $\mathrm{mAC/IL/ACN} \mathrm{10/1/20,10/2/20,} \mathrm{and} \mathrm{10/3/20.} \mathrm{The} \mathrm{mixture}$ was refluxed at $303 \mathrm{~K}$ for 50 minutes and then, the temperature was elevated to $355 \mathrm{~K}$ to evaporate $\mathrm{ACN}$. Next, $0.5 \mathrm{~g}$ of the as prepared specimen was blended with $0.5 \mathrm{~g}$ azobisisobutyronitrile per $30 \mathrm{~mL}$ EtOH solution and agitated at $120 \mathrm{rpm}$ giving $333 \mathrm{~K}$ temperature. Then, the resulting sample (IL@mAC) filtered, washed with EtOH for 3 times, labeled, and kept for further usage [25].

\subsection{Characterization of IL@mAC}

X-ray diffraction (XRD) pattern of IL@mAC was taken in the range of $2 \theta$ values from 5-80 using XRD (Philips PW-1840 diffractometer, Amsterdam, Netherland) with Cu-Ka radiation ( $\lambda=1.54178 \mathrm{~A}$ ) $)$. The magnetic properties of IL@mAC were investigated using vibrating sample magnetometer (VSM) (MDKFD instrument, Iran). The prepared IL@mAC was characterized using scanning electron microscopy (SEM) (Mira 3-XMU apparatus proficient of $700000 \mathrm{x}$ magnifications) for surface morphology determination. The elemental composition analysis of IL@mAC was observed using energy dispersive X-ray snertrncrnnv (FחX) In addition Fnurier transform infra-red spectroscopy (FTIR) was performed with a Loading [MathJax]/jax/output/CommonHTML/jax.js 
Vertex 70 FTIR spectrometer (Broker, Massachusetts, USA). The $\mathrm{N}_{2}$-adsorption/desorption isotherm was obtained to examine the textural characteristics of IL@mAC using a Belsorp-mini II (MicrotracBEL Corp, Japan). Before $\mathrm{N}_{2}$-adsorption/desorption isotherm measurement, the IL@mAC sample was degassed under $10-3 \mathrm{~mm}-\mathrm{Hg}$ at $100^{\circ} \mathrm{C}$. The specific surface area of IL@mAC was calculated using BrunauerEmmett-Teller (BET) and pore diameter was determined by Barrett-Joyner-Halenda (BJH) method. The zero-point charge (ZPC)/isoelectric point of IL@mAC was estimated using $0.01 \mathrm{M} \mathrm{NaCl}$ solutions for initial $\mathrm{pH}\left(\mathrm{pH}_{\mathrm{i}}\right)$ ranging from 2 to 9 . The $\mathrm{pH}_{\mathrm{i}}$ was adjusted using $1 \mathrm{~N}$ aqueous solution of $\mathrm{HCl}$ and $\mathrm{NaOH}$. $\mathrm{A}$ fixed amount $(0.02 \mathrm{~g})$ of IL@mAC was introduced to each pH-adjusted solution followed by stirring for 48 hours. Next, the supernatant was decanted and for each solution, final $\mathrm{pH}\left(\mathrm{pH}_{\mathrm{f}}\right)$ was noted.

\subsection{Adsorption experiments}

Adsorption of TCy from waste-water was measured in batch experiments. The effect of pH (3-11), reaction time (30-240 min), TCy initial concentration (50-1500 mg/L), and IL@mAC dose (0.01-0.1 g/50 $\mathrm{mL}$ ) was deliberated according to the experimental framework defined by central composite design (CCD) methodology (Tables S1 and 1). All the experiments were performed at $303 \mathrm{~K}$ temperature. The working TCy solutions with desired concentrations were prepared by diluting the stock TCy solution and the solutions pHs were adjusted using $0.1 \mathrm{M} \mathrm{HCl}$ or $\mathrm{NaOH}$. After adding a known amounts of IL@mAC into 50 $\mathrm{mL}$ of the working TCy solutions, the aluminum foil-sealed flasks were stirred for a desired time interval. Then, the IL@mAC was separated using $0.22 \mu \mathrm{m}$ syringe filter, and TCy concentration was measured by UV spectrophotometer at the predetermined maximum wavelength. To evaluate the removal efficiency (\%

$\mathrm{R}_{\mathrm{TCy}}$ ) and adsorption capacity of TCy, equations 1 and 2 were used.

$$
\begin{aligned}
& \% R_{T C y}=\frac{C_{0}-C_{e q}}{C_{0}} \times 100 \\
& q_{\text {eq }}=\frac{\left(C_{0}-C_{e q}\right) V}{m}
\end{aligned}
$$

Where, \% $\mathrm{R}_{\mathrm{TCy}}, \mathrm{C}_{\text {eq }}, \mathrm{C}_{\mathrm{o}} \mathrm{q}_{\mathrm{eq}}, \mathrm{V}$ and $\mathrm{m}$ are the removal efficiency of IL@mAC for TCy, final TCy concentration (mg/L), initial concentrations of TCy (mg/L), equilibrium adsorption capacity of IL@mAC for TCy (mg/g), volume (L), and amount of IL@mAC (g) respectively.

Adsorption isotherm studies were conducted th the optimized conditions using TCy solution with primary concentrations of 50-1500 mg/L. Various isotherm equations like Langmuir, Freundlich, and Temkin were analyzed to fit the experimental data.

\subsection{Design and statistical analysis}

Design of experiments and data analyses were conducted by applying CCD approach. The influence of main effective parameters, i.e. amount of IL@mAC (A), pH (B), TCy concentration (C), and contact time (D) -(each at five levels)- was investigated (Table S1). Accordingly, 30 experiments were defined to be carried out Tahle 1 shows the randomized conditions of the relationship between the variables in Loading [MathJax]/jax/output/CommonHTML/jax.js 
different scenarios and the method of performing the experiments. After performing the experiments according to the design, the $\mathrm{R}_{\mathrm{TCy}}$ of TCy by IL@mAC in each step was calculated. All CCD-based calculations were performed using Minitab 16 software. 
Table 1

Operational parameters and their efficacy in TC removal in various methods of performing runs

\begin{tabular}{|lllllll|}
\hline Run & A & B & C & D & \multicolumn{2}{c|}{ \% Removal of TC } \\
\hline 1 & & & & & Experimental & Predicted \\
\hline 2 & 0 & 0 & 0 & 0 & 82.36 & 72.45 \\
\hline 3 & 1 & 1 & 1 & -1 & 93.27 & 89.04 \\
\hline 4 & 0 & 0 & 0 & -2 & 99.90 & 99.90 \\
\hline 5 & 0 & 0 & 0 & 0 & 89.48 & 81.06 \\
\hline 6 & 0 & 0 & 0 & 0 & 78.78 & 75.45 \\
\hline 7 & 1 & -1 & 0 & 1 & 79.04 & 72.00 \\
\hline 8 & 0 & 2 & 1 & 0 & 96.57 & 99.73 \\
\hline 9 & 1 & 1 & 1 & 1 & 80.79 & 70.91 \\
\hline 10 & -1 & 1 & 1 & 1 & 70.68 & 67.03 \\
\hline 11 & -1 & -1 & 1 & 1 & 74.69 & 55.76 \\
\hline 12 & 1 & -1 & 1 & 1 & 84.08 & 65.32 \\
\hline 13 & -1 & 1 & -1 & 1 & 77.14 & 76.70 \\
\hline 14 & 0 & 0 & 0 & 0 & 83.73 & 76.60 \\
\hline 15 & 1 & -1 & 1 & -1 & 86.60 & 82.8 \\
\hline 16 & -1 & -1 & -1 & 1 & 77.14 & 63.68 \\
\hline 17 & -1 & -1 & 1 & -1 & 90.63 & 68.52 \\
\hline 18 & -1 & 1 & 1 & -1 & 79.89 & 77.50 \\
\hline 19 & -2 & 0 & 0 & 0 & 77.14 & 67.74 \\
\hline 20 & -1 & 1 & -1 & -1 & 96.79 & 91.32 \\
\hline 21 & 0 & 0 & -2 & 0 & 77.14 & 66.45 \\
\hline 22 & 0 & 0 & 0 & 2 & 69.99 & 55.20 \\
\hline 23 & 0 & 0 & 0 & 0 & 86.95 & 77.51 \\
\hline 1 & 0 & 0 & 0 & 0 & 87.14 & 80.75 \\
\hline 1 & 1 & -1 & -1 & -1 & 81.49 & 86.63 \\
\hline 14 & & & 83.14 \\
\hline
\end{tabular}




\begin{tabular}{|lllllll|}
\hline Run & A & B & C & D & \multicolumn{2}{l|}{ \% Removal of TC } \\
\hline 26 & 0 & -2 & 0 & 0 & 80.06 & 61.12 \\
\hline 27 & 0 & 0 & 2 & 0 & 65.70 & 50.65 \\
\hline 28 & 2 & 0 & 0 & 0 & 91.44 & 81.59 \\
\hline 29 & 1 & 1 & -1 & -1 & 95.75 & 94.24 \\
\hline 30 & -1 & -1 & -1 & -1 & 89.04 & 82.20 \\
\hline
\end{tabular}

The relationship between independent and dependent variables was described using the second-order polynomial equation represents as:

$Y=a_{0}+a_{1} A+a_{2} B+a_{3} C+a_{4} D+a_{11} A^{2}+a_{22} B^{2}+a_{33} C^{2}+a_{44} D^{2}+a_{12} A B+a_{13} A C+a_{14} A D+a_{23} B C+a_{24} B D+$ $\mathrm{a}_{34} \mathrm{CD} 3$

Where $a_{0}$ represents the constant factor, $a_{1}, a_{2}, a_{3}$, and $a_{4}$ stand for the correlation coefficient demonstrating the linear factors, $a_{11}, a_{22}, a_{33}$, and $a_{44}$ are the correlation coefficients expressing the second-order factors, $a_{34}, a_{24}, a_{23}, a_{14}, a_{13}$, and $a_{12}$ stand for the correlation coefficients of interactive factors. To determine the accuracy, significance, and precision of the given model, the analysis of variance (ANOVA) was conducted. Given $R^{2}, R^{2}$ adj, lack of fit (LOF) statistics and Prob $>F$, the statistical significance of the developed model was determined. Besides the criteria mentioned for estimating the accuracy of model, the difference between experimental and predicted responses (residuals) was determined as well.

\subsection{TCy desorption study}

The recyclability and reusability of as-prepared IL@mAC was carried out, which is a crucial characteristic deciding the economic applicability of an adsorbent in real-scales based on its reuse and desorption capability [26]. For this experiment, a $50 \mathrm{~mL}$ solution of $20 \mathrm{mg} / \mathrm{L}$ TCy was oscillated at $200 \mathrm{rpm}$ after adding $0.015 \mathrm{~g}$ of IL@mAC for $12 \mathrm{~h}$. The $\mathrm{C}_{\text {eq }}$ of TCy was measured in the supernatant and removal efficiency was determined. After first cycle, IL@mAC was magnetically separated, and further remaining TCy was desorbed using 0.1 N NaOH from exhausted IL@mAC [27]. Next, IL@mAC was washed with water, dried and the recovered-dried IL@mAC was utilized again to perform TCy removal applying similar conditions. A total of six cycles were conducted adopting the same procedure.

\section{Results And Discussion}

\subsection{Characterization of IL@mAC}


To evaluate the purity and crystalline nature of IL@mAC, XRD spectrum of IL@mAC was taken (Fig. 1a) and compared with the reference XRD spectrum (Card No. 926 - 91) from the Joint Powder Diffraction Standards Committee (JCPDS). The XRD pattern of the synthesized IL@mAC is in good agreement with the standard $\mathrm{Fe}_{3} \mathrm{O}_{4}$, indicating that the magnetic core is stable during functionalization. The magnetic properties of IL@mAC were calculated using a VSM hysteresis loop as shown in Fig. 1b. These magnetic properties of IL@mAC, comprising saturation magnetization (MS; illustrates the material magnetization carried at a higher applied value of an external magnetic field $\mathrm{H})$, remnant magnetization (Mr; this determines the residual magnetization after removing external magnetic field), and coercivity (Hc; this calculates the reverse field, which is required for magnetization to reach zero after saturation) are estimated to be $35.3 \mathrm{emu} / \mathrm{g}, 0.38 \mathrm{emu} / \mathrm{g}$, and $20.71 \mathrm{G}$, respectively. Hence, the low Hc value of IL@mAC validates that the prepared material contains super-magnetic properties.

The SEM micrographs of IL@mAC are shown in Fig. 2a, b. The morphology of IL@mAC shows a rough and porous surface. This perforated nature of the developed sample let more opportunity to adsorb pollutants from an aqueous media. Moreover, Fig. 2 also confirms that the surface layer of mAC has been covered by IL, which in turn, makes the surface smoother. The EDX analysis of the IL@mAC is shown in Fig. 2c, which was performed before TCy adsorption. In Fig. 2c, results show the elemental composition of prepared IL@mAC, eventually confirming the composition (C, O, Ca, Fe). The EDX results strongly revealed that IL@mAC formation using complete precursors with no impurity in the sample.

The $\mathrm{N}_{2}$-adsorption/desorption isotherm of IL@mAC was evaluated at $77 \mathrm{~K}$ to identify the pore structure and surface area and shown in Fig. 3b. Before measurement, the water humidity was removed by heating under vacuum at $423 \mathrm{~K}$. The isotherm of IL@mAC obeys type I. The Brunauer-Emmett-Teller (BET) surface area $\left(S A_{B E T} ; m^{2} \cdot g^{-1}\right)$, pore sizes $(D ; n m)$, and pore volume $\left(V_{\text {total }} ; \mathrm{cm}^{3} \cdot \mathrm{g}^{-1}\right)$ of IL@mAC are found to be $220.39 \mathrm{~m}^{2} \cdot \mathrm{g}^{-1}, 8.36 \mathrm{~nm}$, and $14.097 \mathrm{~cm}^{3} \cdot \mathrm{g}^{-1}$ respectively. Therefore, the large surface area and large $V_{\text {total }}$ are two of the factors involved in adsorption efficiency that confirm the high and efficient adsorption removal ability of IL@mAC for TCy. It can be assumed that the modification of mAC with IL is responsible for increased surface area and decrease pore size of IL@mAC, which enhances the adsorption capability of AC resulting in efficient adsorption of TCy. Other factors responsible for high and efficient adsorption capacity of IL@mAC are discussed in Sect. 3.4.

To prove that the IL was bonded to the mAC, the FTIR spectrum of as-synthesized IL@mAC was taken as shown in Fig. 3a. The peak at $3527 \mathrm{~cm}^{-1}$ is related to the $-\mathrm{OH}$ group. The characteristic peak of Fe-O bond is observed at $580 \mathrm{~cm}^{-1}$. Frequencies ranging from $2600 \mathrm{~cm}^{-1}$ to $3000 \mathrm{~cm}^{-1}$ are assigned to the $\mathrm{C}-\mathrm{H}$ symmetric and asymmetric stretching vibrations and at $2683 \mathrm{~cm}^{-1}$ the peak can be associated to the $\mathrm{C} \equiv \mathrm{N}$ stretching vibration. The peak at $1640 \mathrm{~cm}^{-1}$ is assigned to the vibration of heteroaromatic $\mathrm{C}-\mathrm{H}$ bond and the $\mathrm{C}-\mathrm{N}$ vibration is appeared at $1570 \mathrm{~cm}^{-1}$. The peak of the FTIR spectrum at $1689 \mathrm{~cm}^{-1}$ indicates that it is associated to the amide group's tensile band. So, this peak proves that the IL adheres to the surface of the mAC covalently by forming an amide bond. 
The ZPC describes the $\mathrm{pH}$ whereupon the adsorbent surface bears no charge due to the absence of adsorption, negatively (-) charged at $\mathrm{pH}>\mathrm{pH}_{\mathrm{ZPC}}$ and positively (+) charged at $\mathrm{pH}<\mathrm{pH}_{\mathrm{ZPC}}$. The $\mathrm{pH}_{\mathrm{ZPC}}$ value for IL@mAC is approximated by plotting pH difference $\left(\Delta \mathrm{pH}=\mathrm{pH}_{\mathrm{i}}-\mathrm{pH}_{\mathrm{f}}\right)$ as a function of $\mathrm{pH}_{\mathrm{i}}$ whereas the ZPC (isoelectric point) experimental value for IL@mAC is estimated around 6.3 (Fig. S1). So, it may be assumed that IL@mAC holds positive (+) surface charge below pH 6.3 whereas negative (-) above $\mathrm{pH} 6.3$.

\subsection{Model fitting and statistical analysis}

According to Eq. (3), the final equation as coded factors is presented as follow by Eq. (4):

$$
\begin{aligned}
& \text { TCy removal }(\%)=77.14+6.36 \mathrm{~A}-3.42 \mathrm{~B}-8.97 \mathrm{C}+2.87 \mathrm{D}+0.27 \mathrm{AB}+0.56 \mathrm{AC}-1.49 \mathrm{AD}+ \\
& 1.58 \mathrm{BC}+1.91 \mathrm{BD}-0.82 \mathrm{CD}+1.98 \mathrm{~A}^{2}-4.26 \mathrm{~B}^{2}+0.37 \mathrm{C}^{2}-0.35 \mathrm{D}^{2}
\end{aligned}
$$

As can be seen from the above-developed equation, the effect of IL@mAC dose, pH, TCy concentration, and contact time, are significant, of which two second parameters have negative effect on TCy removal. In case of large F-values and small p-values, the parameter effectiveness can be high [28]. The response of the TCy removal procedure by IL@mAC depends significantly on the entire studied parameters, including IL@mAC dose, pH, TCy concentration, and contact time. Therefore, the suggested model can present a good estimation of the experimental results. Also, the insignificant LOF demonstrated the validity of the quadratic model for the current study [29]. According to the results (Table 2), the 2nd order model with $F(F$ model $=9.13)$ and prob $>F(0.0001)$ was significant. The significant model terms in this scenario are $A, B, C, D$, and $B^{2}$ (given the $p<0.05$ ). Whereas the higher $p$-values for $A B, A C, A D, B C, B D, C D$, $A^{2}, C^{2}$ and $D^{2}$ are $0.8616,0.7079,0.3342,0.3509,0.2538,0.5994,0.1019,0.7378$, and 0.7506 , respectively suggesting the insignificant interaction terms (given the $p>0.05$ ). 
Table 2

Experiment design matrix (Contained sets of anticipated and experimental values for TC adsorptive removal onto IL@mAC

\begin{tabular}{|c|c|c|c|c|c|c|}
\hline & $\begin{array}{l}\text { Sum of } \\
\text { squares }\end{array}$ & $\begin{array}{l}\text { Degree of freedom } \\
\text { (df) }\end{array}$ & $\begin{array}{l}\text { Mean } \\
\text { square }\end{array}$ & $\begin{array}{l}\text { F- } \\
\text { value }\end{array}$ & $\begin{array}{l}\mathrm{p}- \\
\text { value }\end{array}$ & \\
\hline Model & 4050.83 & 14 & 289.35 & 9.130 & $\begin{array}{l}< \\
0.0001\end{array}$ & Significant \\
\hline $\begin{array}{l}\text { A-Dose of } \\
\text { IL@mAC }\end{array}$ & 781.09 & 1 & 781.09 & 24.66 & 0.0002 & \\
\hline B-pH & 1712.03 & 1 & 1712.03 & 54.05 & $\stackrel{<}{0.0001}$ & \\
\hline C-Conc. of TC & 230.43 & 1 & 230.43 & 7.270 & 0.0166 & \\
\hline $\begin{array}{l}\text { D-Reaction } \\
\text { time }\end{array}$ & 171.52 & 1 & 171.52 & 5.410 & 0.0344 & \\
\hline$A B$ & 1.00 & 1 & 1.00 & 0.031 & 0.8616 & \\
\hline$A C$ & 4.62 & 1 & 4.62 & 0.150 & 0.7079 & \\
\hline$A D$ & 31.54 & 1 & 31.54 & 1.000 & 0.3342 & \\
\hline $\mathrm{BC}$ & 29.36 & 1 & 29.36 & 0.930 & 0.3509 & \\
\hline $\mathrm{BD}$ & 44.61 & 1 & 44.61 & 1.410 & 0.2538 & \\
\hline$C D$ & 9.12 & 1 & 9.12 & 0.290 & 0.5994 & \\
\hline$A^{2}$ & 96.17 & 1 & 96.17 & 3.040 & 0.1019 & \\
\hline$B^{2}$ & 478.35 & 1 & 478.35 & 15.10 & 0.0015 & \\
\hline$c^{2}$ & 3.68 & 1 & 3.68 & 0.120 & 0.7378 & \\
\hline$D^{2}$ & 3.32 & 1 & 3.32 & 0.100 & 0.7506 & \\
\hline Residual & 475.14 & 15 & 31.68 & & & \\
\hline Lack of fit & 404.04 & 9 & 44.89 & 3.79 & 0.0595 & $\begin{array}{l}\text { Non- } \\
\text { significant }\end{array}$ \\
\hline Pure Error & 71.10 & 6 & 11.85 & & & \\
\hline Cor. Total & 4525.97 & 29 & & & & \\
\hline
\end{tabular}

Table S2 presents the ANOVA for response. In order to decide the polynomial model quality, adjusted RSquared $\left(R^{2}\right.$ adj $)$ and $R^{2}$ have been implemented i.e., 0.797 and 0.895 , respectively. The model capability to charasterize the rhannes in the recnnnce ic increased, if $R^{2}$ is closer to 1 . In fact, it ensures the fitness of Loading [MathJax]/jax/output/CommonHTML/jax.js 
2nd order model for experimental data. Consequently, one can reliably use the presented model for the response optimization [30]. The predicted R-Squared $\left(R^{2}\right.$ pred $)$ of 0.4297 is reasonably consistent with the $\mathrm{R}^{2}$ adj of 0.797 . Also, "AdEq. Precision" with desirable ratios higher than 4 is used to determine signal to noise ratio. The ratio of 11.338 suggests an adequate signal, showing that the design space can be navigated by the model. The normality of the distribution of residues was verified using the normality plot. Figure 4 shows a chart of nominal (expected) values relative to residual values obtained by applying the tested form of the RSM model. A straight line has been formed by the points on the residuals normal diagram, approving the normal distribution of the residuals [31]. Using CV (coefficient of variations) in Table S2, the results of model reproducibility are described. Given that $\mathrm{CV}<10 \%$ represents the model reproducibility and this model has replicable results (CV value $=0.42 \%$,).

\subsection{Impact of interaction variables}

The Fig. $5(a, b, c)$ shows, as the initial pH is increased from 3 to 7 , the adsorptive removal of TCy is also increased. The solution pH affects the nature of the IL@mAC and TCy. In case the pH is increased from 5 to 7, the \% $\mathrm{R}_{\mathrm{TCy}}$ of IL@mAC towards the TCy is increased gradually. For the $\mathrm{pH}$ value higher than 7, the \% $\mathrm{R}_{\mathrm{TCy}}$ is decreased rapidly. According to the results, the neutral environment is more favorable for the TCy enrichment on IL@mAC and TCy adsorption onto magnetite showed similar behavior [32]. It is primarily because, the pH of solution affects the surface charge of the IL@mAC and the TCy forms in the solution [33]. The value of $\mathrm{pH}$ affects the ionization degree of the TCy molecules. Three chemically distinct acidic functional groups are found in TCy: dimethylamine cation (pKa =9.69), carboxymethyl (pKa =3.30), and phenolic diketone $(\mathrm{pKa}=7.68)$ [34]. Therefore, for solution $\mathrm{pH}<3.30$, the dominant form of TCy in the solution is the $\mathrm{H}_{4} \mathrm{TCy}^{+}$ions. In case the $\mathrm{pH}$ is within the 3.30-7.68 range, TCy can be considered as a negatively charged hydroxyl group and a mixture of a dimethylamino group, where the dominant form is $\mathrm{H}_{3}$ TCy. In case the $\mathrm{pH}$ is within the 7.68-9.69 range, the dominant form of TCy is the $\mathrm{H}_{2} \mathrm{TCy}^{-}$ions. In case the solution $\mathrm{pH}>9.69$, the dominant form of TCy is $\mathrm{HTCy}_{2}{ }^{-}$. Given that the ZPC of IL@mAC is found to be 6.3, the surface charge of IL@mAC is positive below pH 6.3 and negative above pH 6.3. Although both TCy and IL@mAC are of positive charge at pH below 6.3, whilst the maximum removal is observed, which indicates involvement of hydrogen bonding, $\pi-\pi$ interaction along with electrostatic interactions between the surface of IL@mAC and TCy molecule [35]. Similar results were reported by Figueroa et al. [36] and Rakshit et al. [37] as well. When the $\mathrm{pH}$ is raised from 3 to 5 , amphoteric TCy ions, $\mathrm{H}_{3} T C y$, and other TCy forms found in the solution were primarily seized by IL@mAC via hydrogen, ligand exchange, and electrostatic reactions or slightly positive or negative charge of IL@mAC surface minimized the electrostatic/repulsive attraction with $\mathrm{H}_{3} \mathrm{TCy}[35,38]$. In case of $\mathrm{pH}>9$, the electrostatic repulsion is formed between the negatively charged IL@mAC and the negatively charged $\mathrm{HTCy}^{2-}$, leading to the rapid reduction of TCy adsorptive removal onto IL@mAC. At pHs less than 5 and above 7, the tendency of the adsorbent and adsorbate is reduced due to the neutral surface charge of one of them relative to each other, which reduces the removal efficiency $[39,40]$. The obtained results are also consistent with the results obtained by Guyer et al. [41]. 
A major effective factor for increasing the adsorption efficiency is the IL@mAC dose, because as the nanoparticle dose is increased, the surface area possessed by adsorbate for the exchange adsorption is increased [40]. Evidently, as the IL@mAC dose is increased from 0.06 to $0.09 \mathrm{~g} / 50 \mathrm{~mL}$ at pH = 7, the efficiency of TCy removal is increased ranging from 75.44-82.52\%. In addition, Fig. 5 a shows that the highest efficiency of TCy removal (> 82\%) is observed at IL@mAC dose of $0.06 \mathrm{~g} / 50 \mathrm{~mL}$.

The contact time is another factor effective in the adsorption procedure. Figure $5(c, e, f)$ shows the effect of interaction of contact time with pH, TCy concentration and IL@mAC dose. Figure $5 c$ suggests that at the neutral $\mathrm{pH}$, when the contact time is prolonged to $135 \mathrm{~min}$, the removal efficiency is increased from $66.9-77.2 \%$. For TCy adsorption procedure, TCy transference from the solution phase takes place into the IL@mAC pores and around the adsorption site. At times higher than $135 \mathrm{~min}$, the adsorption efficiency remains constant and does not change, probably due to the completion of the adsorption capacity of the IL@mAC. According to Fig. 5f, the interaction study between contact time and various TCy concentrations indicate that when the initial concentration of TCy is increased, the adsorption efficiency is decreased. Therefore, the higher rate of adsorption at the beginning of the adsorption procedure can be attributed to the superficial vacant sites of the IL@mAC that absorb TCy quickly and achieving the equilibrium. As the time passes after beginning of the procedure, the active adsorption sites are decreased and the TCy adsorption onto IL@mAC is declined. As a result, the external surfaces become nearly saturated, and the adsorption is continued as an internal and deep process, retarding the adsorption procedure, by which the efficiency of adsorption is maintained nearly constant [32].

The initial TCy concentration represents a major driving force present for hindering mass transfer from TCy between the solid and aqueous phases [33]. As a result, as the initial concentration of TCy is increased, the removal efficiency declines. At higher doses, the higher TCy concentration leads to higher probability of severe collisions between the IL@mAC surface and TCy molecules (Fig. 5). According to Fig. $5(\mathrm{~b}, \mathrm{~d}, \mathrm{f})$ the maximum removal efficiency of $88.75 \%$ is obtained at $\mathrm{pH} 7,0.06 \mathrm{~g} / 50 \mathrm{~mL}$ dosage of IL@mAC, temperature $303 \mathrm{~K}$ and TCy concentration of $775 \mathrm{mg} / \mathrm{L}$. Further it can be observed that removal efficiency of TCy is increased as the pH increased till 7 and decreased as concentration of TCy increased. The removal efficiency of $83.7 \%$ is observed at pH 7, 0.06 g/50 mL IL@mAC dose and $412 \mathrm{mg} / \mathrm{L}$ TCy concentration and when the similar conditions are used for $1137.5 \mathrm{mg} / \mathrm{L} \mathrm{TCy}$, a decreased $(70 \%)$ removal efficiency is observed. Form Fig. 5 , it can be observed that the optimum conditions are found to be $\mathrm{pH} 7$, IL@mAC dose $0.06 \mathrm{~g} / 50 \mathrm{~mL}$, time 135 min where maximum removal ( 88\%) efficiency is achieved.

\subsection{Mechanism of TCy adsorption onto IL@mAC}

The TCy functional groups can undergo many electronic coupling interactions such as $\pi-\pi$ EDA (electron donor acceptor), hydrogen bonding, and electrostatic interactions. Almost no TCy molecule carries net electrical charge within the 3-8 $\mathrm{pH}$ range, which results in hardly producing electrostatic attraction with IL@mAC. A low TCy sorption at the elevated pH values (i.e. pH > 9) was observed, and at pH values lower than $\sim 9$, the sorption was higher because of the EDA interactions occurred between bulk $\pi$ systems on IL@mAC surface and TCy molecules contained both double bonds and benzene rings, or hydrogen

Loading [MathJax]/jax/output/CommonHTML/jax.js orption mechanism [42]. At pH > 9, the adsorption efficiency 
will decline because of the similar charges present between TCy and IL@mAC, indicating that the electrostatic interaction is the driving force of the adsorption. Moreover, It has also been reported that pore/size-selective adsorption is considered as a one of the major factors for TCy adsorption, where TCy is easily entered into the pores of IL@mAC because of their small molecular size (TCy: $0.403 \mathrm{~nm}^{3}$ ) [43]. Furthermore, $\pi-\pi$ and hydrogen bonding interaction between TCy and the IL in the mAC are also involved for TCy adsorption [34]. Besides, hydroxyl, amine, phenol, and enone moieties of TCy may develop hydrogen bonds with hydroxyl and carboxyl functional groups on IL@mAC surfaces [44]. Another reason for formation of cation $\pi$ bonding interactions is the easily protonated amine group at C4 of TCy [45], which is another desirable mechanism of TCy sorption [46]. The proposed mechanism for TCy removal by IL@mAC is illustrated in scheme 1.

TCy has several polar/ionizing functional groups, including phenols, alcohols, ketones, and amino acids. The surface charge of IL@mAC was positive below pH 6.3 and negative above pH 6.3. Therefore, cation exchange reactions as well as surface complexity between TCy molecules and their respective ions/polar sites are expected to occur at the IL@mAC surface. However, these factors alone could not be the main aspects responsible for the strong uptake of TCy onto IL@mAC. In general, the following mechanisms are proposed for the strong IL@mAC adsorbent interactions to adsorb TCy: (1) van der Waals forces (permanent dipole-induced dipole forces and London dispersion forces), (2) $\pi-\pi$ EDA interaction between electron-bonded electron segments and IL@MAC $\pi$ electrons and (3) cation- $\pi$ bond between amino proton group and IL@mAC $\pi$ - electrons. The TCy molecule has a large flat ring structure. Thus, strong van der Waals forces are likely to occur between the TCy molecule and the IL@mAC surface. The $\pi-\pi$ EDA interaction may be one of the most important non-hydrophobic adsorption forces for TCy removal. The conjugated anon structures of the TCy molecule can act as electron receptors due to the strong acceptance of electrons in the ketone group, and therefore strongly interact with the IL@mAC ( $\pi$-electrondonor) surface of adsorbents via $\pi-\pi$ interactions. Recently, the similar interactions of $\pi-\pi$ EDA for nitroaromatic compounds ( $\pi$-electron-acceptor) with carbon-based adsorbents such as graphene ( $\pi$-electrondonors), graphite, coal and carbon nanotubes has been proposed [47-49]. The results of the present study show that the selection and adsorption efficiency can be improved through specific molecular level interactions between organic contaminants and IL@mAC.

\subsection{Modeling of TCy adsorption onto IL@mAC}

To obtain equilibrium data and apply different equilibrium models, the experiment was performed at $\mathrm{pH} 7$ and temperature $303 \mathrm{~K}$ using $1.2 \mathrm{~g} / \mathrm{L}$ IL@mAC dose in TCy initial concentration range from 50 to 1500 $\mathrm{mg} / \mathrm{L}$ and agitated for $135 \mathrm{~min}$ (Fig S2). From the Fig S2, it can be observed that as the TCy initial concentration is increased the adsorption capacity increased from 40 to $815 \mathrm{mg} / \mathrm{g}$ and removal efficiency decreased from $\sim 98$ to $\sim 65 \%$. The competition between increased TCy molecules for less reaction sites onto IL@mAC could be the reason of diminution in \% removal when the TCy concentration increased from 50 to 1500 mg/L. To further investigate the adsorption of TCy onto IL@mAC, the adsorption isotherms are applied, which not only provide real information about adsorption capacity of IL@mAC, but alen a doonor undorctandina of tho roantinn mechanism depending which model is best fitted to data. Loading [MathJax]/jax/output/CommonHTML/jax.js

Page 15/30 
Equilibrium adsorption capacity $\left(\mathrm{q}_{\mathrm{eq}}\right)$ and final equilibrium concentration $\left(\mathrm{C}_{\mathrm{eq}}\right)$ after equilibrium are utilized to define the equilibrium. The isotherms can describe the reaction mechanisms between the adsorbent (IL@mAC) and adsorbed material (TCy).

The three models named Langmuir, Freundlich, and Temkin are applied on equilibrium data of TCyIL@mAC system. The equations representing these models are given in supplementary data (Section S1). From plotting and fitting of adsorption models and determining correlation coefficient $\left(R^{2}\right)$, it can be predicted that which of the adsorption model is more appropriate and compatible with the experimental data of the adsorption process. The Langmuir parameters, $\mathrm{q}_{\mathrm{L}}$ and $\mathrm{b}_{\mathrm{L}}$ are estimated from intercept and slop of plot $1 / q_{\text {eq }}$ vs. $1 / C_{\text {eq }}$ (Fig. S3a), Freundlich constants, $k_{F}$ and $n$ are determined from intercept and slop of plot $\log \mathrm{q}_{\mathrm{eq}}$ vs. $\log \mathrm{C}_{\mathrm{eq}}$ (Fig. S3b), and Temkin constants, $B$ and $\mathrm{a}_{\mathrm{T}}$ are measured from slop and intercept of plot $\mathrm{q}_{\mathrm{eq}} \mathrm{vs} \ln \mathrm{C}_{\mathrm{eq}}$ (Fig. S3c). The calculated parameters (models constants and $\mathrm{R}^{2}$ ) from all models are presented in Table 3.

Table 3

Isotherm parameters of TC on

IL@mAC

\begin{tabular}{|lcc|}
\hline \multicolumn{3}{|l|}{ Langmuir isotherm } \\
\hline $\mathrm{b}_{\mathrm{L}}$ & $\mathrm{q}_{\mathrm{L}}$ & $\mathrm{R}^{2}$ \\
\hline 0.0605 & 666.7 & 0.9977 \\
\hline \multicolumn{3}{|l|}{ Freundlich isotherm } \\
\hline $\mathrm{k}_{\mathrm{F}}$ & $1 / \mathrm{n}$ & $\mathrm{R}^{2}$ \\
\hline 48.27 & 0.5027 & 0.9412 \\
\hline Temkin isotherm & \\
\hline $\mathrm{B}$ & $\mathrm{a}_{\mathrm{T}}$ & $\mathrm{R}^{2}$ \\
\hline 131.3 & 0.924 & 0.9536 \\
\hline
\end{tabular}

Considering the $\mathrm{R}^{2}$ for different models, it can be deduced that adsorption of TCy onto IL@mAC is fitted with all models in decreasing order, Langmuir (0.9977), Freundlich (0.9412), and Temkin (0.9536). Higher $\mathrm{R}^{2}$ value obtained from Langmuir model reveals that Langmuir is the best suited model to explain the mechanism of TCy adsorption onto IL@mAC. These findings suggest a monolayer adsorption of TCy onto homogeneous nature and surface of IL@mAC. Furthermore, the suitability of Langmuir model on experimental data also explains an indirect interaction between TCy and loss in the adsorption heat due to surface coverage. Besides, the estimated values of $b_{L}(0.0605)$ and adsorption intensity $(1 / n=0.5027)$ 
than 1). Consequently chemisorption/physisorption occurs during removal of TCy onto IL@mAC [38]. Further the higher value of B estimated from Temkin model demonstrates a strong interaction force between IL@mAC (adsorbent) and TCy (adsorbate). The positive value of B indicates that the adsorption process of TCy onto IL@mAC was endothermic [50].

The Langmuir adsorption capacity is very useful tool to compare the adsorption efficiency to other adsorbents reported in literature. The adsorption capacity of IL@mAC for TCy is compared with other reported adsorbents in the literature and presented in Table 4. From the comparison, it can be observed that IL@mAC has much greater adsorption capacity for TCy as compared to other state of art adsorbents listed in Table 4. Thus, IL@mAC could be an effective alternative to other state of art adsorbents.

Table 4

Comparison of IL@mAC adsorption capacity with TCy reported adsorbents

\begin{tabular}{|lll|}
\hline Adsorbent & Adsorption capacity $(\mathrm{mg} / \mathbf{g})$ & Reference \\
\hline $\mathrm{H}_{3} \mathrm{PO}_{4}$ modified biochar & 552.0 & {$[51]$} \\
\hline Zirconia nanoparticles & 526.3 & {$[52]$} \\
\hline MWCNT/MIL-53(Fe) & 364.4 & {$[53]$} \\
\hline Modified rice straw derived biochar & 98.33 & {$[54]$} \\
\hline Fe/Mn oxides loaded biochar & 14.24 & {$[55]$} \\
\hline (GO/CA) composite fibers & 131.6 & {$[56]$} \\
\hline Pistachio shell coated with ZnO nanoparticles & 95.05 & {$[57]$} \\
\hline Modified tea waste biochar & 293.4 & {$[58]$} \\
\hline Magnetic Fe/porous carbon hybrid & 1301 & {$[59]$} \\
\hline WS-ACP & 281.4 & {$[38]$} \\
\hline Eu doped SrAl ${ }_{2} \mathrm{O}_{4}$ composites & 26.24 & {$[60]$} \\
\hline Boric acid activated carbon & 173.9 & {$[61]$} \\
\hline IL@mAC & 666.7 & This study \\
\hline
\end{tabular}

\subsection{Recyclability of IL@mAC}

If the adsorbed pollutants cannot be desorbed from the adsorbent materials, the adsorbents need to be disposed and cannot be recycled several times, then the nano-adsorbent itself becomes the 
accessed to verify its repeated binding with TCy and outcomes of adsorption-regeneration-desorption cycles have been presented in Fig. 6. The result outcomes in Fig. 6 indicates that IL@mAC could be regenerated and reused without any significant decrease in its TCy adsorption capacity. Consequently, the removal efficiency of IL@mAC to remove TCy remains around 85\% after six cycles. Due to smaller particle size, IL@mAC has more pores for diffusion, therefore the desorption amount of TCy on IL@mAC is steady with desorption efficiency [27]. The decrease in removal efficiency after 6th cycle might be due to the loss of IL@mAC adsorbent during recycling. These findings indicate that IL@mAC has the potential to be regenerated and reused many times for TCy removal. Therefore, it is possible to recycle and reuse IL@mAC to remove water pollutants, which makes IL@mAC of special economic and environmental importance.

\section{Conclusions}

In this research work, the AC was converted into MAC and then modified with IL to produce a novel adsorbent, IL@mAC (ionic liquid modified magnetic activated carbon). After that the IL@mAC was characterized and applied as adsorbent to remove TCy from water. IL@mAC owned plentiful functional groups and well-developed pore structure as well as quite high specific surface area. The results showed that all the parameters studied (i.e. initial TCy concentration, IL@mAC dose, contact time, and pH) are significantly effective on TCy adsorption onto IL@mAC. The highest removal efficiency ( 88\%) was achieved using $0.06 \mathrm{~g} / 50 \mathrm{~mL}$ of IL@mAC in $135 \mathrm{~min}$ at pH 7 and temperature $303 \mathrm{~K}$ as obtained from 3D plots. The greatest effect on removal of TCy was observed for pH and amount of IL@mAC followed by contact time. The simultaneous effect of all these variables on removal efficiency of TCy was investigated and the obtained results were confirmed by the cases of random effects of different variables relative to each other. The adsorption progression of TCy was well stimulated by Langmuir model and the Langmuir monolayer adsorption capability was found to be $666.7 \mathrm{mg} / \mathrm{g}$. H-bonding, electrostatic interaction, ion complexation and $\pi-\pi$ interaction were the probable mechanisms contributive to the adsorptive removal of TCy onto IL@mAC. The findings indicates that the IL@mAC is of a high practical value having advantageous performance as an adsorbent and could be an alternative adsorbent for TCy elimination from water. The adsorption capacity of IL@mAC reported in this study is enormously superior compared to most of the adsorbents already reported.

\section{Declarations}

\section{Credit author statement}

Edris Bazrafshan: Data curation, Writing - Original draft preparation Amin Allah Zarei: Methodology, Writing - Original draft preparation Leili Mohammadi: Conceptualization, Methodology, Funding acquisition Muhammad Nadeem Zafar: Supervision, Conceptualization, Writing - Reviewing \& editing Maryam Foroughi: Visualization, Investigation Summan Aman: Writing - Reviewing \& editing Faezeh Sabri: Software Amir Hossein Mahvi: Validation, Resources Farahnaz Barahuie: Formal analysis. 


\section{Declaration of Competing Interest}

There is no competing financial interest between the authors.

\section{Acknowledgement}

Research reported here is supported by Elite Researcher Grant Committee under award number [982953] from the National Institutes for Medical Research Development (NIMAD), Tehran, Iran. The project is in accordance with the ethical principles and the national norms and standards for conducting Medical Research in Iran (IR. NIMAD.REC.1398.088).

\section{References}

1. C. Du, Z. Zhang, G. Yu, H. Wu, H. Chen, L. Zhou, Y. Zhang, Y. Su, S. Tan, L. Yang, J. Song, S. Wang, A review of metal organic framework (MOFs)-based materials for antibiotics removal via adsorption and photocatalysis, Chemosphere, 272 (2021) 129501.

2. H. Zhang, P. Liu, Y. Feng, F. Yang, Fate of antibiotics during wastewater treatment and antibiotic distribution in the effluent-receiving waters of the Yellow Sea, northern China, Marine pollution bulletin, 73 (2013) 282-290.

3. M. Foroughi, H.R.S. Arezoomand, A.R. Rahmani, G. Asgari, D. Nematollahi, K. Yetilmezsoy, M.R. Samarghandi, Electrodegradation of tetracycline using stainless steel net electrodes: Screening of main effective parameters and interactions by means of a two-level factorial design, Korean Journal of Chemical Engineering, 34 (2017) 2999-3008.

4. Y. Chao, L. Yang, H. Ji, W. Zhu, J. Pang, C. Han, H. Li, Graphene-analogue molybdenum disulfide for adsorptive removal of tetracycline from aqueous solution: equilibrium, kinetic, and thermodynamic studies, Environmental Progress \& Sustainable Energy, 36 (2017) 815-821.

5. G. Hou, X. Hao, R. Zhang, J. Wang, R. Liu, C. Liu, Tetracycline removal and effect on the formation and degradation of extracellular polymeric substances and volatile fatty acids in the process of hydrogen fermentation, Bioresource technology, 212 (2016) 20-25.

6. S. Rodriguez-Mozaz, S. Chamorro, E. Marti, B. Huerta, M. Gros, A. Sànchez-Melsió, C.M. Borrego, D. Barceló, J.L. Balcázar, Occurrence of antibiotics and antibiotic resistance genes in hospital and urban wastewaters and their impact on the receiving river, Water research, 69 (2015) 234-242.

7. L. Hou, H. Zhang, X. Xue, Ultrasound enhanced heterogeneous activation of peroxydisulfate by magnetite catalyst for the degradation of tetracycline in water, Separation and Purification Technology, 84 (2012) 147-152.

8. A. Garcia-Rodríguez, V. Matamoros, C. Fontàs, V. Salvadó, The influence of light exposure, water quality and vegetation on the removal of sulfonamides and tetracyclines: a laboratory-scale study, Chemosphere, 90 (2013) 2297-2302.

9. Q. Yi, Y. Gao, H. Zhang, H. Zhang, Y. Zhang, M. Yang, Establishment of a pretreatment method for Loading [MathJax]/jax/output/CommonHTML/jax.js $\mathrm{ig}$ enhanced hydrolysis, Chemical Engineering Journal, 300 
(2016) 139-145.

10. F. Liu, W. Zhang, W. Chen, J. Wang, Q. Yang, W. Zhu, J. Wang, One-pot synthesis of NiFe2O4 integrated with EDTA-derived carbon dots for enhanced removal of tetracycline, Chemical Engineering Journal, 310 (2017) 187-196.

11. J. Ou, M. Mei, X. Xu, Magnetic adsorbent constructed from the loading of amino functionalized Fe304 on coordination complex modified polyoxometalates nanoparticle and its tetracycline adsorption removal property study, Journal of Solid State Chemistry, 238 (2016) 182-188.

12. H. Kaur, G. Hippargi, G.R. Pophali, A. Bansiwal, Biomimetic lipophilic activated carbon for enhanced removal of triclosan from water, Journal of Colloid and Interface Science, 535 (2019) 111-121.

13. L. Bulgariu, L.B. Escudero, O.S. Bello, M. Iqbal, J. Nisar, K.A. Adegoke, F. Alakhras, M. Kornaros, I. Anastopoulos, The utilization of leaf-based adsorbents for dyes removal: A review, Journal of Molecular Liquids, 276 (2019) 728-747.

14. A.A. Oladipo, M.A. Abureesh, M. Gazi, Bifunctional composite from spent "Cyprus coffee" for tetracycline removal and phenol degradation: Solar-Fenton process and artificial neural network, International journal of biological macromolecules, 90 (2016) 89-99.

15. H. Pignon, C. Brasquet, P. Le Cloirec, Coupling ultrafiltration and adsorption onto activated carbon cloth: application to the treatment of highly coloured wastewaters, Water science and technology, 42 (2000) 355-362.

16. L.C. Oliveira, R.V. Rios, J.D. Fabris, V. Garg, K. Sapag, R.M.J.C. Lago, Activated carbon/iron oxide magnetic composites for the adsorption of contaminants in water, 40 (2002) 2177-2183.

17. R.C. Bansal, M. Goyal, Activated carbon adsorption, CRC press, 2005.

18. J.-W. Shim, S.-J. Park, S.-K.J.C. Ryu, Effect of modification with $\mathrm{HNO}$ and $\mathrm{NaOH}$ on metal adsorption by pitch-based activated carbon fibers, 39 (2001) 1635-1642.

19. S. Dashamiri, M. Ghaedi, K. Dashtian, M.R. Rahimi, A. Goudarzi, R. Jannesar, Ultrasonic enhancement of the simultaneous removal of quaternary toxic organic dyes by CuO nanoparticles loaded on activated carbon: central composite design, kinetic and isotherm study, Ultrasonics sonochemistry, 31 (2016) 546-557.

20. P. Meng, X. Fang, A. Maimaiti, G. Yu, S.J.C. Deng, Efficient removal of perfluorinated compounds from water using a regenerable magnetic activated carbon, 224 (2019) 187-194.

21. G. Feiqiang, L. Xiaolei, J. Xiaochen, Z. Xingmin, G. Chenglong, R. Zhonghao, Characteristics and toxic dye adsorption of magnetic activated carbon prepared from biomass waste by modified one-step synthesis, Colloids and Surfaces A: Physicochemical and Engineering Aspects, 555 (2018) 43-54.

22. E. Aliyari, M. Alvand, F.J.R.A. Shemirani, Modified surface-active ionic liquid-coated magnetic graphene oxide as a new magnetic solid phase extraction sorbent for preconcentration of trace nickel, 6 (2016) 64193-64202.

23. J. Chen, Y. Wang, Y. Huang, K. Xu, N. Li, Q. Wen, Y.J.A. Zhou, Magnetic multiwall carbon nanotubes modified with dual hydroxy functional ionic liquid for the solid-phase extraction of protein, 140 
24. M. Muneeb Ur Rahman Khattak, M. Zahoor, B. Muhammad, F.A. Khan, R. Ullah, N.M. AbdEl-Salam, Removal of Heavy Metals from Drinking Water by Magnetic Carbon Nanostructures Prepared from Biomass \%J Journal of Nanomaterials, 2017 (2017) 10.

25. M. Muneeb Ur Rahman Khattak, M. Zahoor, B. Muhammad, F.A. Khan, R. Ullah, N.M.J.J.o.N. AbdEISalam, Removal of heavy metals from drinking water by magnetic carbon nanostructures prepared from biomass, 2017 (2017).

26. Z. Noorimotlagh, S.A. Mirzaee, S.S. Martinez, S. Alavi, M. Ahmadi, N.J.C.E.R. Jaafarzadeh, Design, Adsorption of textile dye in activated carbons prepared from DVD and CD wastes modified with multi-wall carbon nanotubes: Equilibrium isotherms, kinetics and thermodynamic study, (2018).

27. Q. Zhou, Z. Li, C. Shuang, A. Li, M. Zhang, M. Wang, Efficient removal of tetracycline by reusable magnetic microspheres with a high surface area, Chemical Engineering Journal, 210 (2012) 350356.

28. N. Gharibzadeh, E. Fatehifar, R. Alizadeh, A. Haghlesan, M. Chavoshbashi, Modeling and optimization of removal of toluene from aqueous solutions using iron oxide nanoparticles by RSM method, Modares Civil Engineering Journal, 16 (2016) 203-213.

29. J. Parsa, M. Abbasi, Modeling and optimizing of sonochemical degradation of Basic Blue 41 via response surface methodology, Open Chemistry, 8 (2010) 1069-1077.

30. H. Zarei, A. Mahvi, S. Nasseri, R. Nabizadeh Noudehi, F. Shemirani, Modeling adsorption on fluoride and application of Box-Behnken design and response surface methodology for arsenic (V) removal from aqueous solution using Nano-Scale Alumina on Multi Walled Carbon Nanotube, Iranian Journal of Health and Environment, 8 (2015) 309-322.

31. S. Ahmadi, L. Mohammadi, A. Rahdar, S. Rahdar, R. Dehghani, C.A. Igwegbe, G.Z. Kyzas, Acid dye removal from aqueous solution by using neodymium(III) oxide nanoadsorbents, Nanomaterials, 10 (2020) Article no. 556.

32. W.W. Ngah, M. Hanafiah, Adsorption of copper on rubber (Hevea brasiliensis) leaf powder: Kinetic, equilibrium and thermodynamic studies, Biochemical Engineering Journal, 39 (2008) 521-530.

33. O. Gulnaz, A. Kaya, S. Dincer, The reuse of dried activated sludge for adsorption of reactive dye, Journal of Hazardous Materials, 134 (2006) 190-196.

34. C. Chen, X. Feng, S. Yao, lonic liquid-multi walled carbon nanotubes composite tablet for continuous adsorption of tetracyclines and heavy metals, Journal of Cleaner Production, 286 (2021) 124937.

35. S. Rakshit, D. Sarkar, E.J. Elzinga, P. Punamiya, R. Datta, Surface complexation of oxytetracycline by magnetite: Effect of solution properties, Vadose Zone Journal, 13 (2014) 1-10.

36. R.A. Figueroa, A. Leonard, A.A. MacKay, Modeling tetracycline antibiotic sorption to clays, Environmental science \& technology, 38 (2004) 476-483.

37. S. Rakshit, E.J. Elzinga, R. Datta, D. Sarkar, In situ attenuated total reflectance Fourier-transform infrared study of oxytetracycline sorption on magnetite, Journal of environmental quality, 42 (2013) 822-827. 
38. C. Zhao, W. Yin, J. Xu, Y. Zhang, D. Shang, Z. Guo, Q. Wang, J. Wang, Q. Kong, Removal of Tetracycline from Water Using Activated Carbon Derived from the Mixture of Phragmites australis and Waterworks Sludge, ACS Omega, 5 (2020) 16045-16052.

39. G. Zhao, J. Li, X. Ren, C. Chen, X. Wang, Few-layered graphene oxide nanosheets as superior sorbents for heavy metal ion pollution management, Environmental science \& technology, 45 (2011) 1045410462.

40. S. Ahmadi, L. Mohammadi, A. Rahdar, S. Rahdar, R. Dehghani, C.A. Igwegbe, G.Z. Kyzas, Acid dye removal from aqueous solution by using neodymium (III) oxide nanoadsorbents, Nanomaterials, 10 (2020) 556.

41. G.T. Güyer, N.H. Ince, Degradation of diclofenac in water by homogeneous and heterogeneous sonolysis, Ultrasonics sonochemistry, 18 (2011) 114-119.

42. R. Deng, D. Huang, G. Zeng, J. Wan, W. Xue, X. Wen, X. Liu, S. Chen, J. Li, C. Liu, Decontamination of lead and tetracycline from aqueous solution by a promising carbonaceous nanocomposite: Interaction and mechanisms insight, Bioresource technology, 283 (2019) 277-285.

43. J. Rivera-Utrilla, C.V. Gómez-Pacheco, M. Sánchez-Polo, J.J. López-Peñalver, R. Ocampo-Pérez, Tetracycline removal from water by adsorption/bioadsorption on activated carbons and sludgederived adsorbents, Journal of Environmental Management, 131 (2013) 16-24.

44. H. Zarei, A. Mahvi, S. Nasseri, R.N. Noudehi, F. Shemirani, Modeling adsorption on fluoride and application of Box-Behnken design and response surface methodology for arsenic $(V)$ removal from aqueous solution using nano-scale alumina on multi walled carbon nanotube, Iranian Journal of Health and Environment, 8 (2015).

45. L. Ji, W. Chen, L. Duan, D. Zhu, Mechanisms for strong adsorption of tetracycline to carbon nanotubes: a comparative study using activated carbon and graphite as adsorbents, Environmental science \& technology, 43 (2009) 2322-2327.

46. L. Ji, Y. Wan, S. Zheng, D. Zhu, Adsorption of tetracycline and sulfamethoxazole on crop residuederived ashes: implication for the relative importance of black carbon to soil sorption, Environmental Science \& Technology, 45 (2011) 5580-5586.

47. J. Chen, W. Chen, D. Zhu, Adsorption of Nonionic Aromatic Compounds to Single-Walled Carbon Nanotubes: Effects of Aqueous Solution Chemistry, Environmental Science \& Technology, 42 (2008) 7225-7230.

48. W. Chen, L. Duan, D. Zhu, Adsorption of Polar and Nonpolar Organic Chemicals to Carbon Nanotubes, Environmental Science \& Technology, 41 (2007) 8295-8300.

49. D. Zhu, J.J. Pignatello, Characterization of Aromatic Compound Sorptive Interactions with Black Carbon (Charcoal) Assisted by Graphite as a Model, Environmental Science \& Technology, 39 (2005) 2033-2041.

50. J. Chang, Z. Shen, X. Hu, E. Schulman, C. Cui, Q. Guo, H. Tian, Adsorption of Tetracycline by Shrimp Shell Waste from Aqueous Solutions: Adsorption Isotherm, Kinetics Modeling, and Mechanism, ACS 
51. T. Chen, L. Luo, S. Deng, G. Shi, S. Zhang, Y. Zhang, O. Deng, L. Wang, J. Zhang, L. Wei, Sorption of tetracycline on H3PO4 modified biochar derived from rice straw and swine manure, Bioresource Technology, 267 (2018) 431-437.

52. B. Debnath, M. Majumdar, M. Bhowmik, K.L. Bhowmik, A. Debnath, D.N. Roy, The effective adsorption of tetracycline onto zirconia nanoparticles synthesized by novel microbial green technology, Journal of Environmental Management, 261 (2020) 110235.

53. W. Xiong, G. Zeng, Z. Yang, Y. Zhou, C. Zhang, M. Cheng, Y. Liu, L. Hu, J. Wan, C. Zhou, R. Xu, X. Li, Adsorption of tetracycline antibiotics from aqueous solutions on nanocomposite multi-walled carbon nanotube functionalized MIL-53(Fe) as new adsorbent, Science of The Total Environment, 627 (2018) 235-244.

54. J. Dai, X. Meng, Y. Zhang, Y. Huang, Effects of modification and magnetization of rice straw derived biochar on adsorption of tetracycline from water, Bioresource Technology, 311 (2020) 123455.

55. X. Zhang, Y. Li, M. Wu, Y. Pang, Z. Hao, M. Hu, R. Qiu, Z. Chen, Enhanced adsorption of tetracycline by an iron and manganese oxides loaded biochar: Kinetics, mechanism and column adsorption, Bioresource Technology, 320 (2021) 124264.

56. H. Zhu, T. Chen, J. Liu, D. Li, Adsorption of tetracycline antibiotics from an aqueous solution onto graphene oxide/calcium alginate composite fibers, RSC Advances, 8 (2018) 2616-2621.

57. A.A. Mohammed, S.L. Kareem, Adsorption of tetracycline fom wastewater by using Pistachio shell coated with ZnO nanoparticles: Equilibrium, kinetic and isotherm studies, Alexandria Engineering Journal, 58 (2019) 917-928.

58. B. Li, Y. Huang, Z. Wang, J. Li, Z. Liu, S. Fan, Enhanced adsorption capacity of tetracycline on tea waste biochar with $\mathrm{KHCO} 3$ activation from aqueous solution, Environmental Science and Pollution Research, (2021).

59. W. Gu, X. Huang, Y. Tian, M. Cao, L. Zhou, Y. Zhou, J. Lu, J. Lei, Y. Zhou, L. Wang, Y. Liu, J. Zhang, High-efficiency adsorption of tetracycline by cooperation of carbon and iron in a magnetic Fe/porous carbon hybrid with effective Fenton regeneration, Applied Surface Science, 538 (2021) 147813.

60. B. Turan, M. Bugdayci, K. Benzesik, P. Demircivi, Synthesis of Eu doped SrAl204 composite: adsorption characteristics on tetracycline and ciprofloxacin antibiotics, Separation Science and Technology, (2021) 1-12.

61. M. Yuan, C. Li, B. Zhang, J. Wang, J. Zhu, J. Ji, Y. Ma, A mild and one-pot method to activate ligninderived biomass by using boric acid for aqueous tetracycline antibiotics removal in water, Chemosphere, 280 (2021) 130877.

\section{Figures}



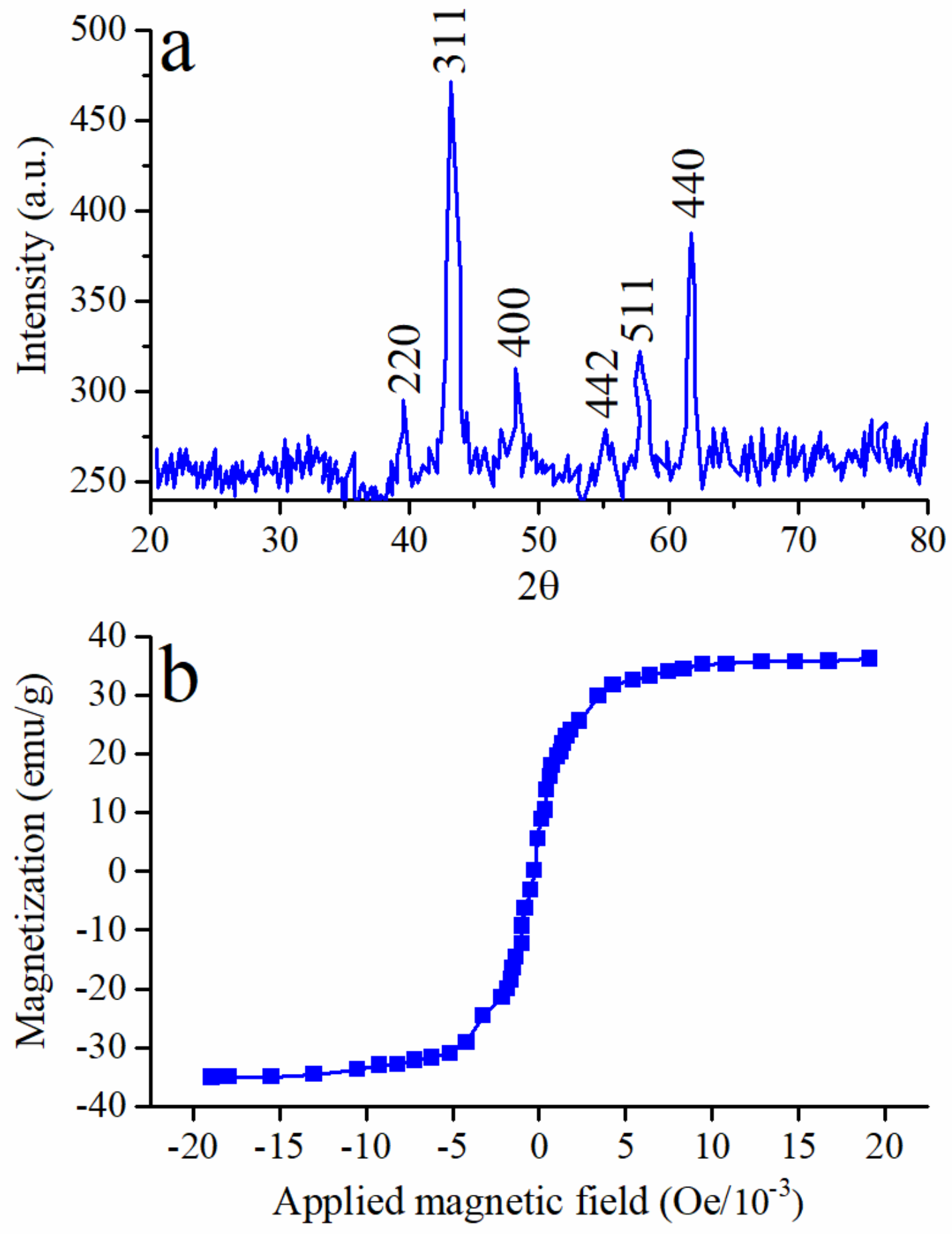

Figure 1

XRD pattern (a) and VSM (b) of the prepared IL@mAC 


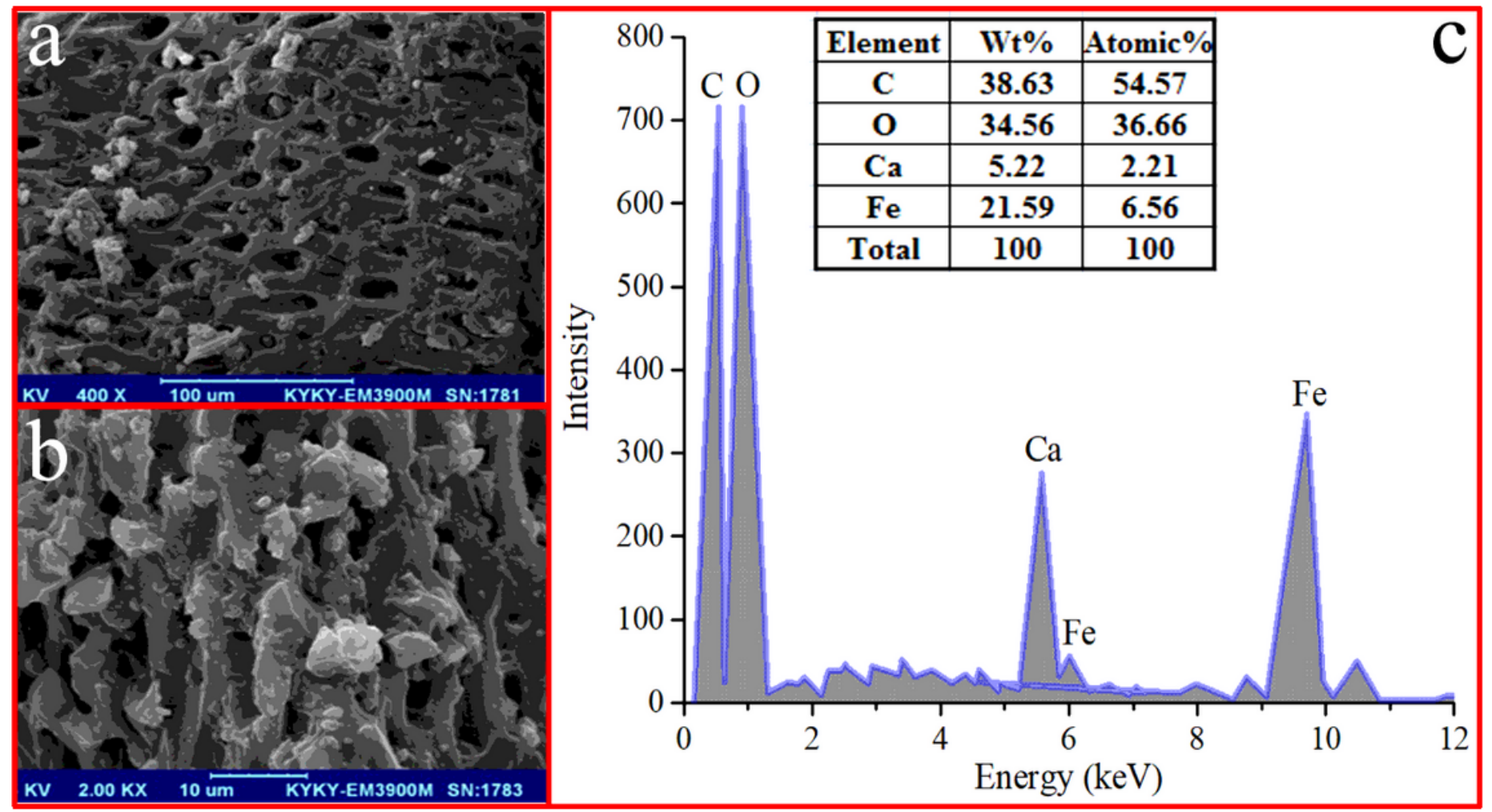

Figure 2

SEM images at (a) low and (b) high magnification and (c) EDX analysis of IL@mAC 

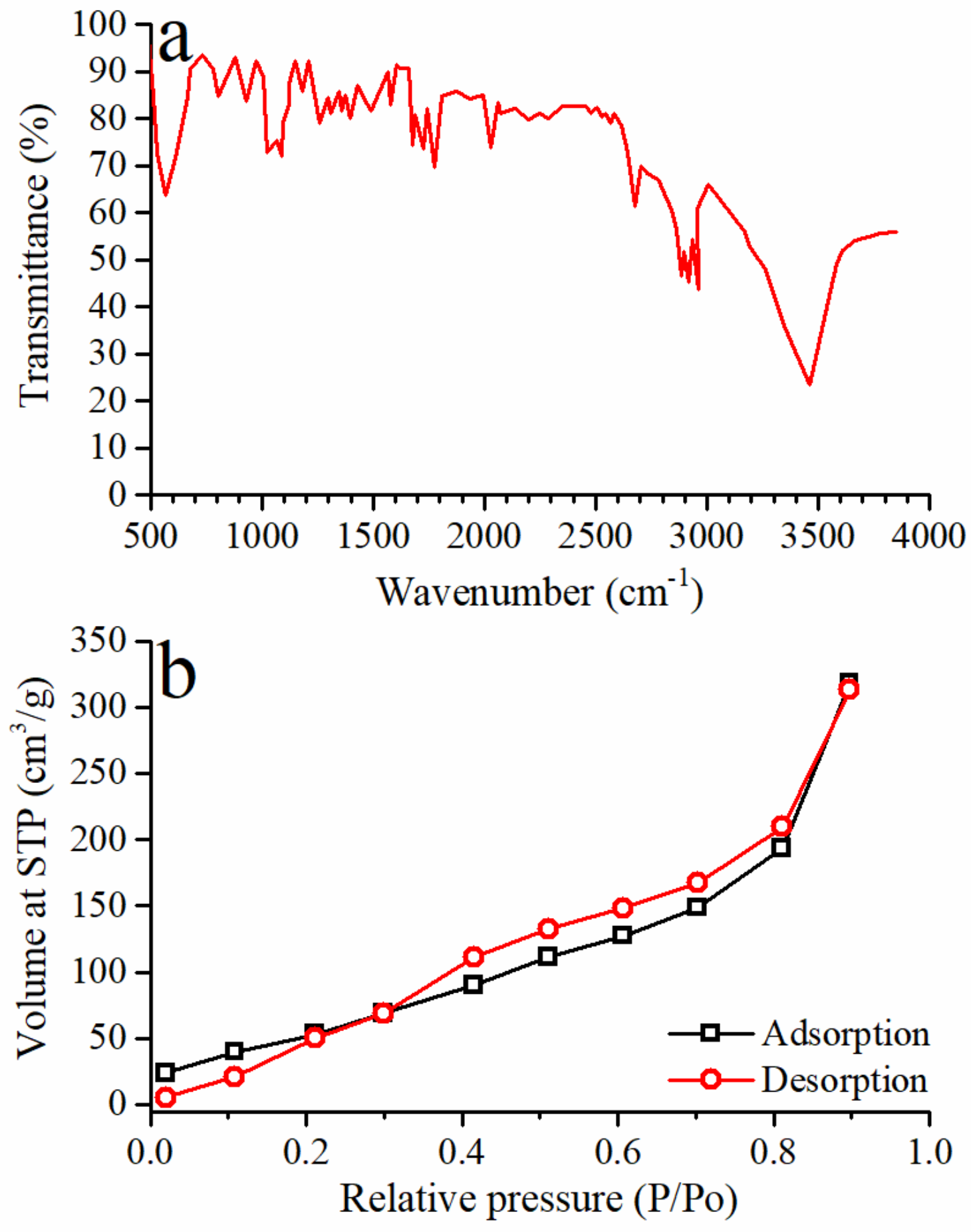

Figure 3

(a) FTIR spectra and (b) nitrogen adsorption/desorption isotherm of IL@mAC 
Normal Plot of Residuals

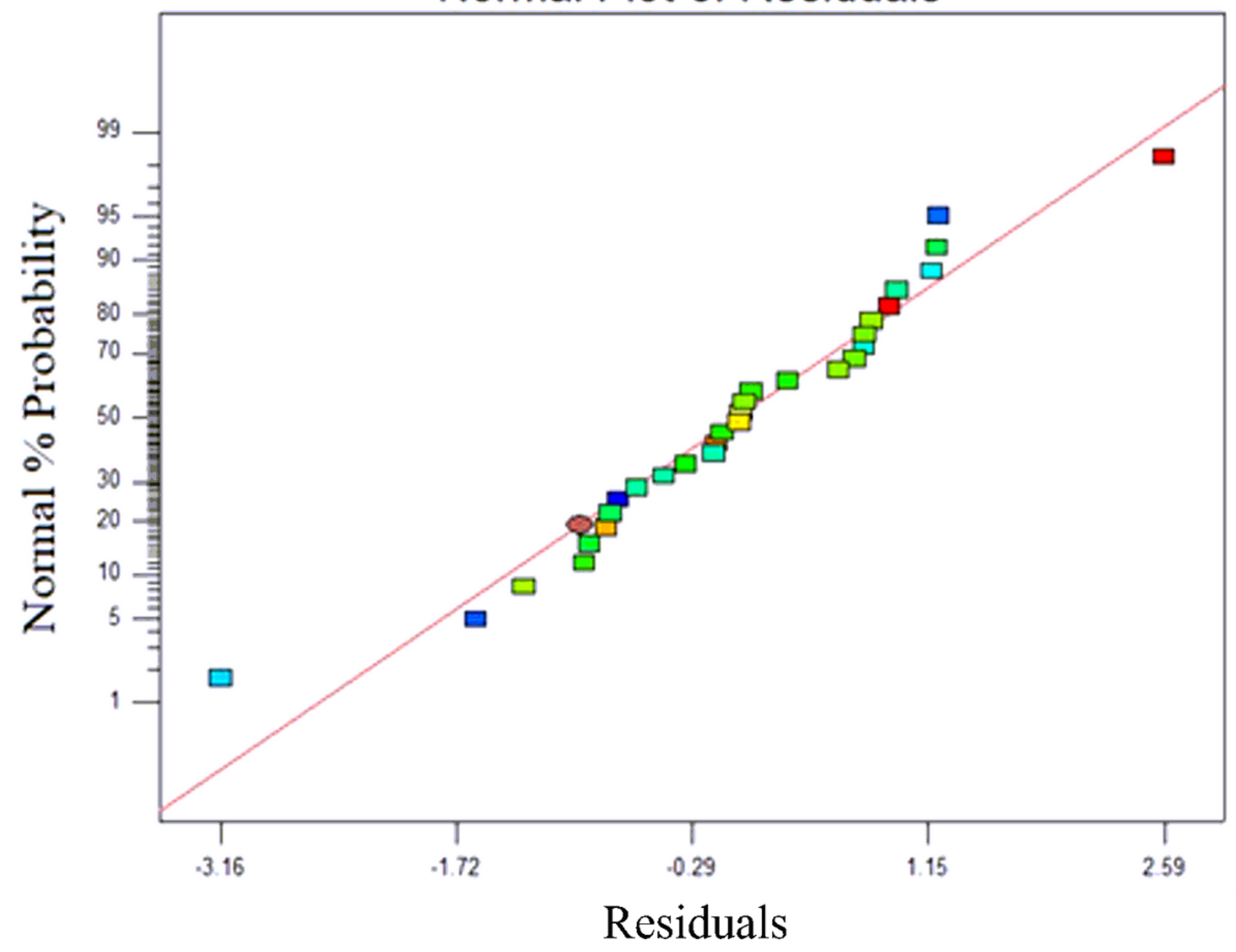

Figure 4

The normal plot of residuals for estimation of the normal distribution of residuals for tetracycline removal onto IL@mAC 


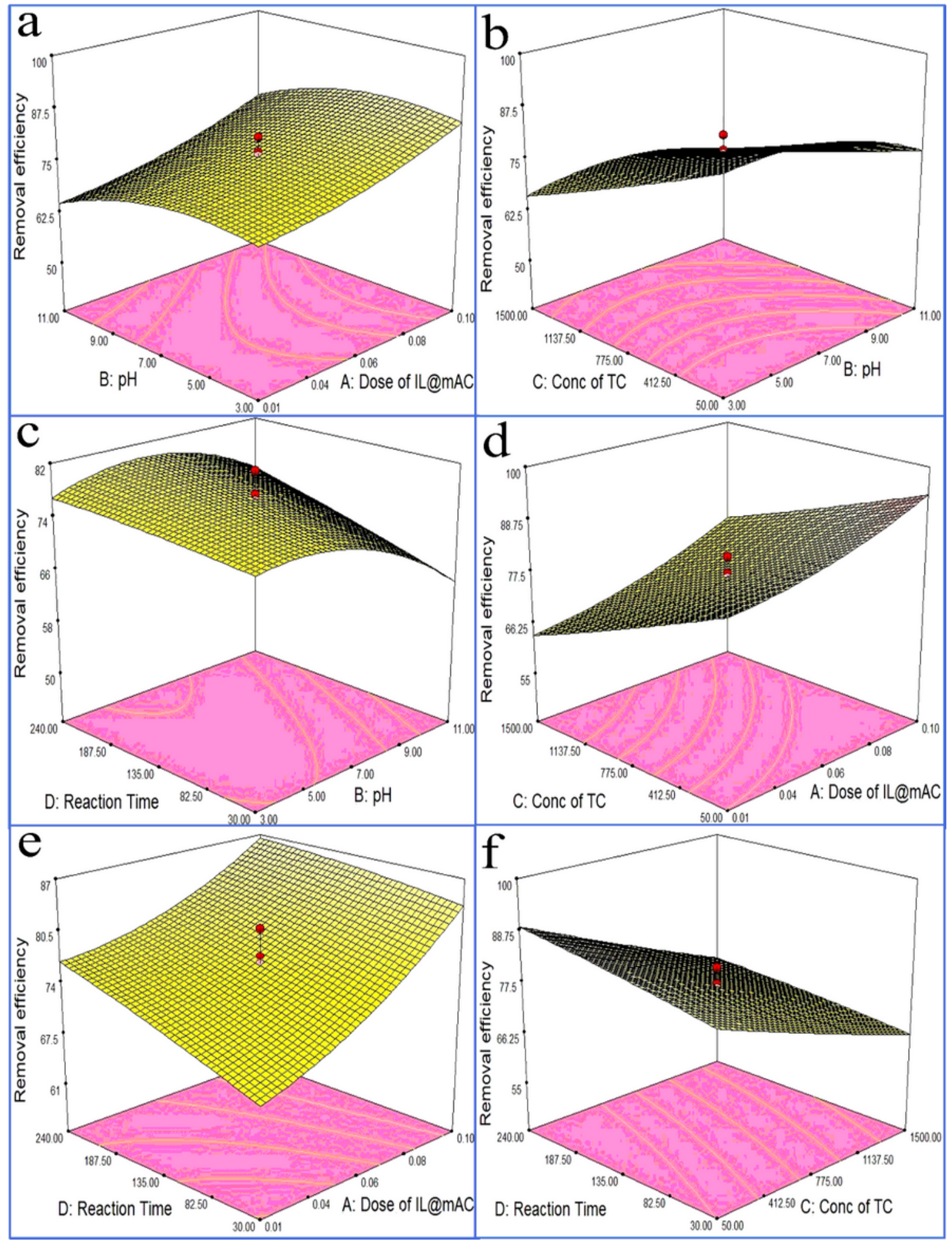

Figure 5

Response surface plots of the predicted TC adsorptive removal percentage as a function of (a) $\mathrm{pH}$ and IL@mAC amount, (b) tetracycline concentration and $\mathrm{pH}$, (c) reaction time and $\mathrm{pH}$, (d) tetracycline concentration and IL@mAC amount, (e) reaction time and IL@mAC amount, and (f) reaction time and tetracycline concentration, keeping other variables at central point levels 


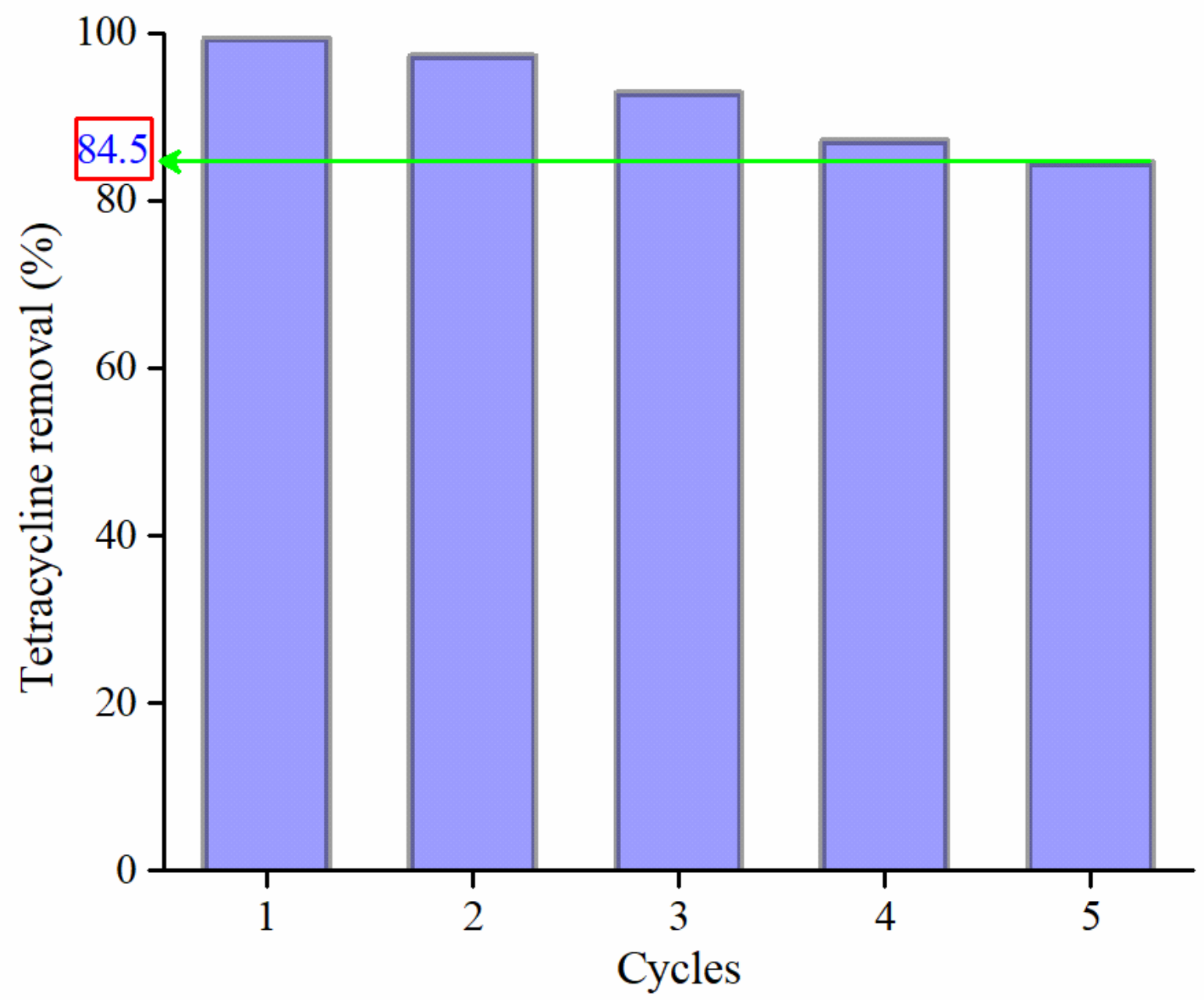

Figure 6

Recycling of IL@mAC for tetracycline 


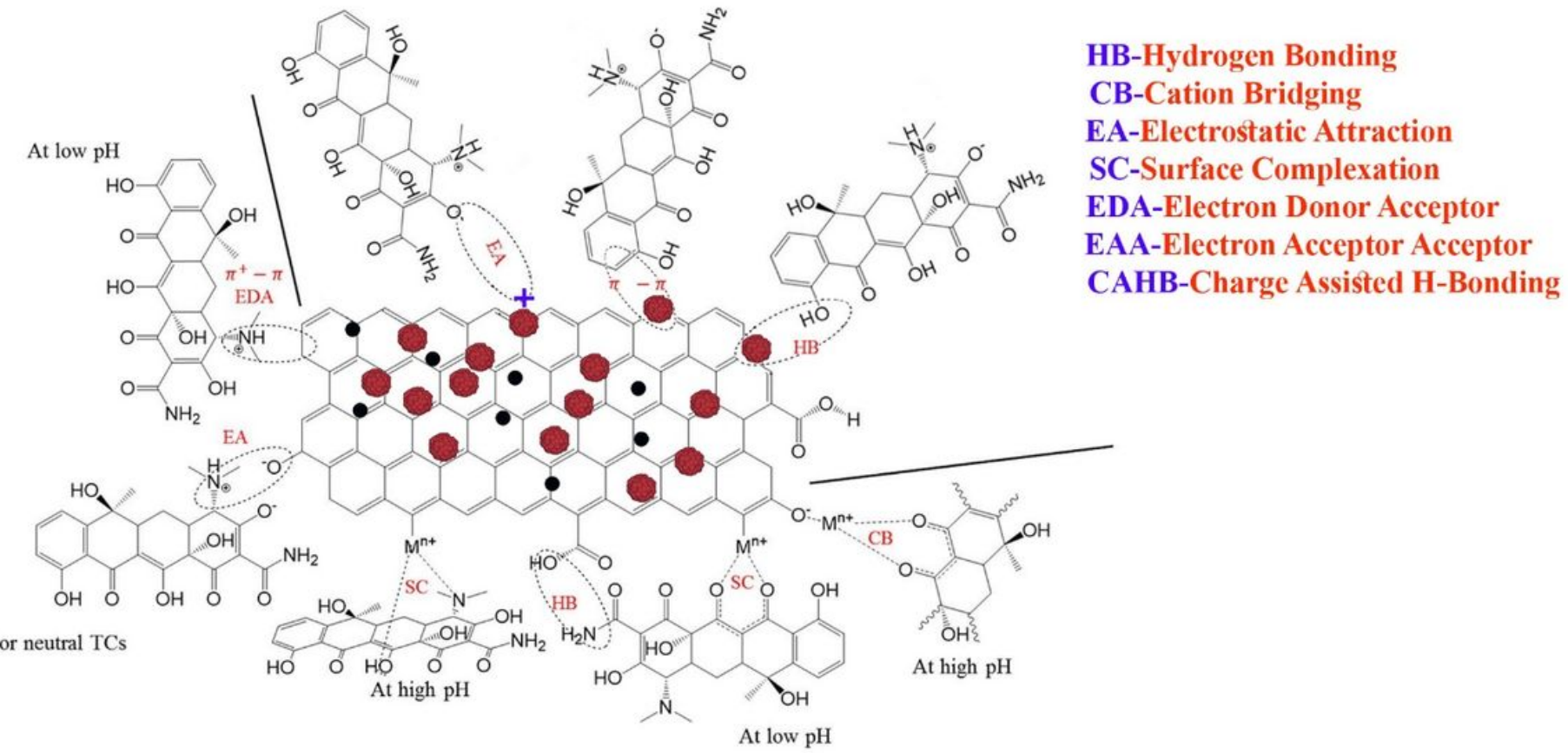

Figure 7

Scheme 1. Mechanisms of tetracycline removal onto IL@mAC

\section{Supplementary Files}

This is a list of supplementary files associated with this preprint. Click to download.

- RevisedSupplementarydata.docx

- Onlinefloatimage8.png 